\title{
Effects of dyslexia on postural control in
}

\section{adults}

\author{
Patel $\mathrm{M}^{1}$, Magnusson $\mathrm{M}^{1}$, Lush $\mathrm{D}^{2}$, Gomez $\mathrm{S}^{3} \&$ Fransson $\mathrm{PA}^{1}$.
}

${ }^{1}$ Department of Otorhinolaryngology Head and Neck surgery,

Clinical Sciences, Lund, Lund University, S-221 85 Lund, Sweden.

${ }^{2}$ Faculty of Applied Sciences,

University of the West of England, Bristol BS16 1QY, Great Britain.

${ }^{3}$ University of Plymouth, 3-15 Endsleigh Place, Drake Circus,

Plymouth PL4 8AA, Great Britain.

Running title: Adult dyslexia and postural stability

\section{Acknowledgement}

The authors would like to acknowledge the contributions from Mary Haslum of valuable discussions on the topic

\section{Address for correspondence:}

Fransson PA, Department of Otorhinolaryngology Head and Neck surgery,

Clinical Sciences, Lund, Lund University,

S-221 85 Lund, Sweden

Phone: Int. + 46, 46 171705; Fax: Int. + 46, 462110968

E-mail: Per-Anders.Fransson@med.lu.se 


\begin{abstract}
Developmental dyslexia has been shown to affect postural control. The aim of the present study was to investigate the difference in postural stability measured as torque variance in an adult dyslexic group $(n=14$, determined using the Adult Dyslexia Checklist (ADCL) and nonsense word repetition test) and an adult non-dyslexic group $(\mathrm{n}=39)$ on a firm surface and on a foam block and with eyes open and eyes closed. Another aim was to investigate the correlation between ADCL scores and postural stability.

Findings showed that ADCL scores correlated with torque variance in the anteriorposterior direction on foam with eyes closed $(p=0.001)$ and in the lateral direction on foam surface with eyes closed $(p=0.040)$ and open $(p=0.010)$. General Linear Model analysis showed that high dyslexia scores associated with increased torque variance $(p<0.001)$. However, we found no significant difference between dyslexics and non-dyslexics, though there were indications of larger torque variance in the dyslexics.

The findings suggest that adults with high dyslexic ADCL scores may experience subclinical balance deficits. Hence, it is motivated to assess the motor ability and postural control in those with high ADCL scores.
\end{abstract}

Keywords: Developmental dyslexia; Postural stability; Attention; Foam; Balance 


\section{Introduction}

Developmental dyslexia, or dyslexia, affects around $10 \%$ of the population and is often characterised by a failure to attain the literacy skills appropriate for a given age, ability and educational level (Rochelle \& Talcott, 2006), and these deficits persist with age. However, dyslexia occurs in the absence of obvious physiological or neurological impairment (Rochelle, Witton, \& Talcott, 2008). Dyslexia has also been associated with a number of additional symptoms, including impairments in visual and motor skills (Nicolson et al., 1999) and a decrease in the speed of information processing (Wright, Bowen, \& Zecker, 2000) suggesting a far more complex disorder.

In an attempt to explain these underlying impairments one theory that has been proposed by Nicolson, Fawcett and co-workers is an automaticity/cerebellar theory, or cerebellar hypothesis, suggesting that the function of the cerebellum is mildly affected by dyslexia (Fawcett \& Nicolson, 1999; Nicolson \& Fawcett, 1990; Nicolson et al., 1999; Stoodley, Fawcett, Nicolson, \& Stein, 2005), and cognitive difficulties ensue. The cerebellum is involved in the integration of information from sensory receptors and is also one location where the internal representation of the body mechanics is computed (Bastian, 2006). The cerebellum is central to the coordination and smoothness of movement (Diedrichsen, Criscimagna-Hemminger, \& Shadmehr, 2007), including balance responses, probably by modulating the timing and amplitude of movement (Smith, 1993). These responses are normally learnt and stored through repetition and become automatic. In the cerebellar hypothesis, of dyslexia, these deficits in motor coordination and smoothness compromise speech articulation leading to inappropriate phonological representations and reading and writing skills (Ramus et al., 2003).

The cerebellar hypothesis predicts that postural control is compromised in dyslexics by a failure to automate postural responses in response to balance perturbations, and thereby 
increasing the requirement for attentional resources to monitor the postural control system. Yet, dyslexics have attention deficiencies (Nicolson \& Fawcett, 1990; Petkov, O'Connor K, Benmoshe, Baynes, \& Sutter, 2005), characterised by their difficulty in reading and performing component skills (Rochelle et al., 2008), which may leave insufficient attentional resources for the maintenance of postural control. Postural control relies upon the appropriate integration of sensory information from the visual, vestibular and somatosensory receptors to the central nervous system (CNS) (Fabbri, Martoni, Esposito, Brighetti, \& Natale, 2006; Schlesinger, Redfern, Dahl, \& Jennings, 1998), but especially when information from any of the sensory systems is not reliable (Redfern, Jennings, Martin, \& Furman, 2001). One way this theory has been tested has been to compare perturbed postural control between dyslexic and non-dyslexic children and this has shown an association between decreased balance control and dyslexia (Fawcett \& Nicolson, 1999; Moe-Nilssen, Helbostad, Talcott, \& Toennessen, 2003). However, the perturbation methods used in these studies, with subjects being perturbed by pushes to the back (Fawcett \& Nicolson, 1999) or by a suddenly released weight fixed around the waists of the subjects (Moe-Nilssen et al., 2003) are not commonly used in clinical assessment of balance. Other methods that attempt to increase the demands for attention by employing dual-task paradigms using cognitive and verbal tasks (Fawcett \& Nicolson, 1999; Nicolson et al., 1999; Wimmer, Mayringer, \& Raberger, 1999), may provide a source of uncontrolled measurement variability (Rochelle et al., 2008) since changed arousal and alertness by itself can affect postural sway (Maki \& McIlroy, 1996; Patel, Gomez et al., 2008). However, the studies by Fawcett, Nicolson and colleagues and by Wimmer and colleagues (Fawcett \& Nicolson, 1999; Nicolson et al., 1999; Wimmer et al., 1999) suggest evidence of attention deficits being related to poor postural control in dyslexics. Therefore, we chose to use the common assessment method of postural control to have subjects stand on a foam block (Enbom, Magnusson, \& Pyykko, 1991), which alters postural stability by making 
pressure distribution uncertain (MacLellan \& Patla, 2006; Wu \& Chiang, 1996) and reduces the effectiveness of ankle torque for postural stability (Horak \& Hlavacka, 2001; MacLellan \& Patla, 2006). Also, the sensory deficit caused by standing on foam increases the level of attention required to re-weight the afferent information to the other more reliable receptors (Redfern et al., 2001; Schlesinger et al., 1998). Further stress can be placed on the balance system by having subjects close their eyes, since vision is involved in the fine-tuning of postural responses (Fransson, Gomez, Patel, \& Johansson, 2007; Patel, Fransson, Lush, \& Gomez, 2008; Paulus, Straube, \& Brandt, 1987).

Other theories include: the phonological theory (i.e. dyslexics have a specific impairment in the representation, storage and/or retrieval of speech sounds); the rapid auditory processing theory (dyslexic's phonological deficit is secondary to a more basic auditory deficit), the visual theory (dyslexic's have a visual impairment giving rise to difficulties with the processing of letters and words on a page of text) and the magnocellular theory (i.e. deficits in visual and auditory as well as tactile interpretations) (Ramus et al., 2003).

To date, no study of dyslexia has considered investigating postural stability between a group of non-dyslexic adults and a group of dyslexic adults using foam to perturb standing and with and without visual information to increase the attentional requirement or whether the deficits of dyslexia are proportional to postural instability.

The main aim of this study was to compare postural stability on a firm surface and a foam block between a normal group of adults and a dyslexic group of adults with eyes open and closed. In addition, to determine whether postural stability is a sensitive measure of developmental dyslexia, we aimed to correlate postural performance against scores from the Adult Dyslexia Checklist (ADCL) (Vinegrad, 1994), which has been advocated by the British Dyslexia Association (The British Dyslexia Association, 2009). As previous studies have noted that children with developmental dyslexia often display levels of an increased 
instability following perturbation (Fawcett \& Nicolson, 1999), we hypothesized that adults with dyslexia would display greater levels of instability than non-dyslexic adults when standing on a foam block. We also expected an association between ADCL scores and postural stability.

\section{Materials and Methods}

\subsection{Subjects}

53 subjects ( 25 male and 28 female) aged between 18 and 25 years (mean 21.3 years with a standard deviation (SD) of 1.3 years) volunteered for this study from the student population at the University of the West of England, UK. 11 of these volunteers had already been diagnosed as being dyslexic through official dyslexia testing in the United Kingdom. Their average mass was $68.0 \mathrm{~kg}(\mathrm{SD} 13.0 \mathrm{~kg})$ and average height $168 \mathrm{~cm}(\mathrm{SD} 8 \mathrm{~cm})$. No subject had previously experienced balance problems, central nervous disease or significant injury of the legs, nor were any taking medication. All were asked to refrain from alcohol at least 48 hours prior to testing. Full, informed consent was obtained before any tests were performed, all of which were carried out according to the Helsinki Declaration of 1975 and approved by the local ethics board.

To categorise the subjects into 'non-dyslexic' or 'dyslexic' (Stoet, Markey, \& Lopez, 2007), each subject was asked to complete the Adult Dyslexia Checklist (ADCL) (Vinegrad, 1994) which has been validated by the British Dyslexia Association (The British Dyslexia Association, 2009), see table 1, and perform the nonsense word repetition test (Gathercole, Willis, Baddeley, \& Emslie, 1994). Subjects already diagnosed as dyslexic were all placed in the dyslexic group but were still asked to complete all tests to grade the severity of their difficulty by the ADCL score. 
The ADCL comprised 20 questions requiring a 'yes/no' response aimed at assessing auditory, phonological, cognitive and learning deficits typically evidenced in dyslexia (table 1) (Vinegrad, 1994). Following the test completion, the number of 'yes' responses were summed together yielding a dyslexia score, and a value of 9 or more 'yes' responses was deemed to suggest dyslexia, which is a powerful indicator of difficulty (British Dyslexia Association, 2009). 9 of the 11 previously categorised dyslexic individuals scored 9 or above in the ADCL score test. The 2 remaining, previously diagnosed, dyslexics scored 8 yes responses but showed difficulty in the nonsense word repetition test. Five additional subjects scored 9 and above. Concomitant impairments in the nonsense word repetition test were evaluated if un-diagnosed subjects scored 9 (four subjects). If the subject showed difficulty in the nonsense word repetition test (6 or more incorrect responses from 40 words), he or she was put into the dyslexic group (two subjects). 39 subjects (17 male and 22 female) fell into the non-dyslexic group (average weight $169 \mathrm{~cm}$, SD 8cm; average mass $69.6 \mathrm{~kg}$, SD $13.0 \mathrm{~kg}$ ) and 14 subjects ( 8 male and 6 female) into the dyslexic group (average mass $166 \mathrm{~cm}, \mathrm{SD} 8 \mathrm{~cm}$; average mass $63.8 \mathrm{~kg}$, SD 13.0kg). All of those subjects scoring nine or more 'yes responses' had difficulty in at least seven of the "best twelve" questions for identifying dyslexia (British Dyslexia Association, 2009).

\subsection{Equipment}

The torque to the support surface was recorded using a force platform containing six pressure sensors beneath its surface with an accuracy of $0.5 \mathrm{~N}$. The data from the force platform were sampled at $50 \mathrm{~Hz}$ by a customised computer program which stored all recordings. The torque variance was recorded in the anteroposterior and lateral directions while standing directly on the solid surface of the force platform (dimensions $423 \mathrm{~mm}$ length $\mathrm{x}$ $420 \mathrm{~mm}$ width $\mathrm{x} 117 \mathrm{~mm}$ height) or on a compliant foam block placed on top of the force 
platform (dimensions $467 \mathrm{~mm}$ length $\mathrm{x} 473 \mathrm{~mm}$ width x $136 \mathrm{~mm}$ height; density $82 \mathrm{~kg} / \mathrm{m}^{3}$, elastic modulus 49200 N/m² (Patel, Fransson, Lush, \& Gomez, 2008)).

\subsection{Procedure}

Each subject was asked to stand barefoot on the force platform or on a foam block placed on top of the force platform, in a relaxed posture, with arms folded. The subject's heels were $3 \mathrm{~cm}$ apart and feet at a $30^{\circ}$ angle using guidelines. Subjects either focused on a visual target positioned at eye level on the wall at a distance of about $1.5 \mathrm{~m}$, or had their eyes closed when instructed. Each subject was asked to stand on the firm and foam surfaces twice, once with eyes open (EO) and once with eyes closed (EC), with each of the 4 tests lasting for 30 s. The orders of surface and vision conditions were randomised using a Latin square design to reduce any potential order effect. To avoid fatigue, there was three minutes rest between tests.

Table 1 about here

\subsection{Data Analysis}

Anteroposterior and lateral torque variance was normalised using the subjects' squared height and mass before the statistical analysis in order to compensate for the individual differences in height and mass (Fransson et al., 2007). Torque $\tau$ is calculated from the formula $\tau=\mathrm{CoP}($ Centre of Pressure $) \times \mathrm{Fz}$; where $\mathrm{Fz} \approx \mathrm{m} \cdot \mathrm{g}$; where $\mathrm{m}=$ the assessed subjects mass (in $\mathrm{kg}$ ) and $g=$ gravitational constant 9.81 (in meter $/ \mathrm{s}^{2}$ ), see figure 1. Fz will fluctuate slightly due to present body leaning and when the subject applies additional forces to the surface to accelerate/decelerate a movement. Hence, changes in recorded torque variance are equivalent 
to changes in CoP (Patel, Gomez et al., 2008). It is known that torque is effective in controlling the orientation of a standing organism (Riccio \& Stoffregen, 1988). Also, torque variance values correspond directly to the energy used towards the support surface to maintain stability (Magnusson, Johansson, \& Wiklund, 1990). Furthermore, information about energy is required for perception of the efficiency of standing (Riccio \& Stoffregen, 1988).

\subsection{Statistical Analysis}

Non-parametric statistical tests were used as the Shapiro-Wilk test revealed that the values were not normally distributed. Mann-Whitney statistical tests were used to investigate the differences in torque variance between the dyslexic and non-dyslexic groups. The Spearman's Rank correlation statistical test was used to investigate the relationship between ADCL scores and torque variance with the data combined from the dyslexics and non-dyslexics. Also, a General Linear Model (GLM) univariate Analysis of Variance (ANOVA) was used to investigate the effects of dyslexia score, surface and vision, and their interactions on torque variance. The statistical analysis was carried out with Bonferroni correction for multiple comparisons and the statistical significance levels were set to $p<0.01$ for Mann-Whitney tests and $p<0.05$ for Spearman's Rank correlation and GLM ANOVA tests accordingly (Altman, 1991).

\section{Results}

\subsection{Correlation between ADCL dyslexia scores and torque variance}

There were significant correlations between ADCL dyslexia scores and torque variance in the anteroposterior direction on a foam surface with eyes closed (Coefficient $=0.456, p=$ 0.001, fig. 1A) and in the lateral direction on the foam surface with eyes closed $($ Coefficient $=$ 0.283, $p=0.040$, fig. 1B) and eyes open (Coefficient $=0.353, p=0.010$, fig. $1 \mathrm{C}$ ). On the firm 
surface, there was no significant correlation between dyslexia scores and torque variance with eyes closed or open.

Figure 1 about here

3.2 GLM analysis of ADCL dyslexia scores, surface and vision on torque variance

Table 2 about here

GLM analysis (table 2) revealed that the ADCL dyslexia score, the surface, and the availability of vision significantly affected torque variance in the anteroposterior direction when all participants were considered. Torque variance was larger with higher dyslexia scores, on a foam surface and with eyes closed compared with eyes open. There was also a significant interaction between the surface and vision showing that the contribution of vision to postural stability was greater when standing on a foam surface compared to when standing on a firm surface.

\subsection{Dyslexia and torque variance}

Analysis revealed that the group categorised as dyslexics in the tests, see description above, had larger torque variance than non-dyslexics, particularly on foam, but this could not be evidenced statistically at Bonferroni corrected level of $p<0.01$. However, a detailed 
statistical analysis showed that dyslexics had larger torque variance in the anterior-posterior direction with eyes closed on foam $(p=0.010)$ and on the firm surface $(p=0.037)$, see figure 2 .

Figure 2 about here

\section{Discussion}

\subsection{Dyslexia and balance}

Attention problems are a characteristic of dyslexia (Nicolson \& Fawcett, 1990; Petkov et al., 2005) and attention is well-known to be involved in the integration of sensory information particularly when the information from one or more of the sensory receptors is unreliable (Redfern et al., 2001). These findings can now be complemented with our study findings showing that the balance stability was poorer in those with high dyslexia scores. Although there was no significant interaction between dyslexia scores and the surface condition (i.e. firm or foam), the larger difference between the dyslexic group and the non-dyslexic group on foam, although non-significant, could indicate that dyslexic adults have some difficulty in reweighting their sensory information to the more reliable receptors due to their attentional impairment. Standing on a foam surface alters postural stability by making pressure distribution uncertain (MacLellan \& Patla, 2006; Wu \& Chiang, 1996) and by reducing the effectiveness of ankle torque for postural stability (Horak \& Hlavacka, 2001; MacLellan \& Patla, 2006; Patel, Fransson, Lush, \& Gomez, 2008). An attentional deficiency has also been used to explain the marked differences found between a group of child dyslexics and nondyslexics using double- and single-legged stance by Pozzo et al. (Pozzo et al., 2006). 
Previous studies comparing postural stability in child dyslexics and child non-dyslexics on a normal surface during unperturbed stance have revealed a significant difference between groups with eyes open (Moe-Nilssen et al., 2003; Stoodley et al., 2005) and with both eyes open and closed (Pozzo et al., 2006) and therefore the difference between the results in the present study and that of others could be related to age. As dyslexics get older, compensation could occur for some of the motor deficits. Another possibility is that there appears to be a proportion of adult dyslexic participants with balancing impairment (Stoodley et al., 2005). In this study, some of the participants with high ADCL scoring did not have markedly larger torque variance, whereas in no cases did any subject scoring between 0 and 5 have considerably large torque variance (showed by Figure 1). However, those with high dyslexic scores might be poorer at handling situations where the stability is challenged, e.g., by standing on foam. Furthermore, one other reason why we recorded no significant difference between groups could be the small number of subjects in the dyslexic group.

There is also strong evidence to suggest a genetic co-existence of developmental dyslexia with other disorders such as Attention Deficit Hyperactivity Disorder (ADHD), where there is an over-lap of between 15-40\% (Willcutt, Pennington, Olson, Chhabildas, \& Hulslander, 2005). ADHD is a developmental disorder and is characterised by inattention, motor hyperactivity and impulsivity (Buderath et al., 2008). Besides these behavioural deficits, approximately $50 \%$ of children with ADHD show clumsiness and motor performance below the normal for age (Buderath et al., 2008; Karatekin, Markiewicz, \& Siegel, 2003; Tervo, Azuma, Fogas, \& Fiechtner, 2002). Rochelle et al. have previously found that postural stability in dyslexics is more strongly associated with symptoms of ADHD than those specific to the reading impairment of dyslexia (Rochelle et al., 2008). Though, similar to the cerebellar hypothesis proposed by Nicholson and Fawcett (Nicolson \& Fawcett, 1990), evidence suggests that brain regions like the right-frontal basal ganglia circuitry which has a powerful 
modulatory influence from the cerebellum may have altered volumes in ADHD children (Giedd, Blumenthal, Molloy, \& Castellanos, 2001). Furthermore, dyslexia and ADHD coexist within a disorder known as Developmental Coordination Disorder (DCD) (Crawford \& Dewey, 2008; Willcutt et al., 2005). About 35-50\% of dyslexics have DCD (Kirby, Sugden, Beveridge, Edwards, \& Edwards, 2008), whereas about 50\% of ADHD sufferers have DCD (Buderath et al., 2008). DCD is characterised by lower performance in physical activities that require gross and fine motor coordination than would be expected for an individual's chronological age (Rochelle et al., 2008). Hence, the manifestation of poor postural control in dyslexics could be partially associated with a co-morbidity of either DCD or ADHD. Given the presented results, it is motivated to perform such assessments in further investigations of dyslexia and to consider balance deficits in individuals with ADHD and DCD.

\subsection{ADCL and balance}

The ADCL is composed of questions regarding auditory, phonological, cognitive and learning deficits associated with dyslexia (Vinegrad, 1994). Correlation analysis showed evidence that those with higher dyslexia scores had larger postural instability but only on a foam surface, which perturbs balance (Fransson et al., 2007; Patel, Fransson, Lush, Petersen et al., 2008) and increases the attentional requirement for postural stability (Redfern et al., 2001). Therefore, the more 'yes' responses (i.e. showing difficulty), the more severe the postural deficit in dyslexics may manifest. However, we obtained a correlation despite no large significant difference between the dyslexic and non-dyslexic groups as categorised by the ADCL. Hence, the value of nine "yes" responses for identifying auditory, phonological, cognitive and learning deficits might be appropriate for deeming dyslexia. Our findings suggest that motor deficits are evidence more gradually with increasing dyslexia scores. Thus, another ADCL score limit than the one used for differentiating dyslexics from non-dyslexics, 
might be more appropriate. For example, except for one subject, all participants who scored above twelve showed larger than average torque variance in all tests on a foam surface (e.g. figure 1). Therefore, further testing of the ADCL in the dyslexic population is required though our findings strongly suggest that a high ADCL dyslexia score indicates a greater risk for worse postural stability. Hence, it is motivated to assess the motor ability and postural control in those with high ADCL scores.

\section{Conclusions}

The results in the present study show that adults with high dyslexic ADCL scores display more postural instability that those with low scores.

\section{References}

Altman, D. (1991). Practical statistics for medical research. New York: NY: Chapman \& Hall.

Bastian, A. J. (2006). Learning to predict the future: the cerebellum adapts feedforward movement control. Curr Opin Neurobiol, 16(6), 645-649.

Buderath, P., Gartner, K., Frings, M., Christiansen, H., Schoch, B., Konczak, J., et al. (2008). Postural and gait performance in children with attention deficit/hyperactivity disorder. Gait Posture.

Crawford, S. G., \& Dewey, D. (2008). Co-occurring disorders: a possible key to visual perceptual deficits in children with developmental coordination disorder? Hum Mov Sci, 27(1), 154-169.

Diedrichsen, J., Criscimagna-Hemminger, S. E., \& Shadmehr, R. (2007). Dissociating timing and coordination as functions of the cerebellum. J Neurosci, 27(23), 6291-6301.

Enbom, H., Magnusson, M., \& Pyykko, I. (1991). Postural compensation in children with congenital or early acquired bilateral vestibular loss. Ann Otol Rhinol Laryngol, 100(6), 472478.

Fabbri, M., Martoni, M., Esposito, M. J., Brighetti, G., \& Natale, V. (2006). Postural control after a night without sleep. Neuropsychologia, 44(12), 2520-2525.

Fawcett, A. J., \& Nicolson, R. I. (1999). Performance of Dyslexic Children on Cerebellar and Cognitive Tests. J Mot Behav, 31(1), 68-78.

Fransson, P. A., Gomez, S., Patel, M., \& Johansson, L. (2007). Changes in multi-segmented body movements and EMG activity while standing on firm and foam support surfaces. Eur $J$ Appl Physiol, 101(1), 81-89.

Gathercole, S. E., Willis, C. S., Baddeley, A. D., \& Emslie, H. (1994). The Children's Test of Nonword Repetition: a test of phonological working memory. Memory, 2(2), 103-127.

Giedd, J. N., Blumenthal, J., Molloy, E., \& Castellanos, F. X. (2001). Brain imaging of attention deficit/hyperactivity disorder. Ann N Y Acad Sci, 931, 33-49. 
Horak, F. B., \& Hlavacka, F. (2001). Somatosensory loss increases vestibulospinal sensitivity. J Neurophysiol, 86(2), 575-585.

Karatekin, C., Markiewicz, S. W., \& Siegel, M. A. (2003). A preliminary study of motor problems in children with attention-deficit/hyperactivity disorder. Percept Mot Skills, 97(3 Pt 2), 1267-1280.

Kirby, A., Sugden, D., Beveridge, S., Edwards, L., \& Edwards, R. (2008). Dyslexia and developmental co-ordination disorder in further and higher education-similarities and differences. Does the 'label' influence the support given? Dyslexia, 14(3), 197-213.

MacLellan, M. J., \& Patla, A. E. (2006). Adaptations of walking pattern on a compliant surface to regulate dynamic stability. Exp Brain Res, 173(3), 521-530.

Magnusson, M., Johansson, R., \& Wiklund, J. (1990). Galvanically induced body sway in the anterior-posterior plane. Acta Otolaryngol, 110(1-2), 11-17.

Maki, B. E., \& McIlroy, W. E. (1996). Influence of arousal and attention on the control of postural sway. $J$ Vestib Res, 6(1), 53-59.

Moe-Nilssen, R., Helbostad, J. L., Talcott, J. B., \& Toennessen, F. E. (2003). Balance and gait in children with dyslexia. Exp Brain Res, 150(2), 237-244.

Nicolson, R. I., \& Fawcett, A. J. (1990). Automaticity: a new framework for dyslexia research? Cognition, 35(2), 159-182.

Nicolson, R. I., Fawcett, A. J., Berry, E. L., Jenkins, I. H., Dean, P., \& Brooks, D. J. (1999). Association of abnormal cerebellar activation with motor learning difficulties in dyslexic adults. Lancet, 353(9165), 1662-1667.

Patel, M., Fransson, P. A., Lush, D., \& Gomez, S. (2008). The effect of foam surface properties on postural stability assessment while standing. Gait Posture, 28(4), 649-656.

Patel, M., Fransson, P. A., Lush, D., Petersen, H., Magnusson, M., Johansson, R., et al. (2008). The effects of foam surface properties on standing body movement. Acta Otolaryngol, $1-9$.

Patel, M., Gomez, S., Berg, S., Almbladh, P., Lindblad, J., Petersen, H., et al. (2008). Effects of 24-h and 36-h sleep deprivation on human postural control and adaptation. Exp Brain Res, 185(2), 165-173.

Paulus, W., Straube, A., \& Brandt, T. H. (1987). Visual postural performance after loss of somatosensory and vestibular function. J Neurol Neurosurg Psychiatry, 50(11), 1542-1545.

Petkov, C. I., O'Connor K, N., Benmoshe, G., Baynes, K., \& Sutter, M. L. (2005). Auditory perceptual grouping and attention in dyslexia. Brain Res Cogn Brain Res, 24(2), 343-354.

Pozzo, T., Vernet, P., Creuzot-Garcher, C., Robichon, F., Bron, A., \& Quercia, P. (2006). Static postural control in children with developmental dyslexia. Neurosci Lett, 403(3), 211215.

Ramus, F., Rosen, S., Dakin, S. C., Day, B. L., Castellote, J. M., White, S., et al. (2003). Theories of developmental dyslexia: insights from a multiple case study of dyslexic adults. Brain, 126(Pt 4), 841-865.

Redfern, M. S., Jennings, J. R., Martin, C., \& Furman, J. M. (2001). Attention influences sensory integration for postural control in older adults. Gait Posture, 14(3), 211-216.

Riccio, G. E., \& Stoffregen, T. A. (1988). Affordances as constraints on the control of stance. Human Movement Science, 7(2-4), 265-300.

Rochelle, K. S., \& Talcott, J. B. (2006). Impaired balance in developmental dyslexia? A metaanalysis of the contending evidence. J Child Psychol Psychiatry, 47(11), 1159-1166.

Rochelle, K. S., Witton, C., \& Talcott, J. B. (2008). Symptoms of hyperactivity and inattention can mediate deficits of postural stability in developmental dyslexia. Exp Brain Res.

Schlesinger, A., Redfern, M. S., Dahl, R. E., \& Jennings, J. R. (1998). Postural control, attention and sleep deprivation. Neuroreport, 9(1), 49-52. 
Smith, A. M. (1993). [Babinski and movement synergism]. Rev Neurol (Paris), 149(12), 764770 .

Stoet, G., Markey, H., \& Lopez, B. (2007). Dyslexia and attentional shifting. Neurosci Lett, 427(1), 61-65.

Stoodley, C. J., Fawcett, A. J., Nicolson, R. I., \& Stein, J. F. (2005). Impaired balancing ability in dyslexic children. Exp Brain Res, 167(3), 370-380.

Tervo, R. C., Azuma, S., Fogas, B., \& Fiechtner, H. (2002). Children with ADHD and motor dysfunction compared with children with ADHD only. Dev Med Child Neurol, 44(6), 383390.

The British Dyslexia Association (2009). http://www.bdadyslexia.org.uk/adultchecklist.html

Willcutt, E. G., Pennington, B. F., Olson, R. K., Chhabildas, N., \& Hulslander, J. (2005). Neuropsychological analyses of comorbidity between reading disability and attention deficit hyperactivity disorder: in search of the common deficit. Dev Neuropsychol, 27(1), 35-78.

Wimmer, H., Mayringer, H., \& Raberger, T. (1999). Reading and dual-task balancing: evidence against the automatization deficit explanation of developmental dyslexia. J Learn Disabil, 32(5), 473-478.

Vinegrad, M. (1994). A revised Dyslexia Checklist. Educare, 48.

Wright, B. A., Bowen, R. W., \& Zecker, S. G. (2000). Nonlinguistic perceptual deficits associated with reading and language disorders. Curr Opin Neurobiol, 10(4), 482-486.

Wu, G., \& Chiang, J.-H. (1996). The effects of surface compliance on foot pressure in stance. Gait \& Posture, 4(2), 122-129. 


\section{Tables}

\begin{tabular}{|c|c|c|c|}
\hline & & Yes & No \\
\hline 1. & Do you find difficulty telling left from right? & & \\
\hline 2. & Is map reading or finding your way to a strange place confusing? & & \\
\hline 3. & Do you dislike reading aloud? & & \\
\hline 4. & Do you take longer than you should to read a page of a book? & & \\
\hline 5. & Do you find it difficult to remember the sense of what you have read? & & \\
\hline 6. & Do you dislike reading long books? & & \\
\hline 7. & Is your spelling poor? & & \\
\hline 8. & Is your writing difficult to read? & & \\
\hline 9. & Do you get confused if you have to speak in public? & & \\
\hline 10. & Do you find it difficult to take messages on the telephone and pass them on correctly? & & \\
\hline 11. & When you say a long word, do you sometimes find it difficult to get all the sounds in the right order? & & \\
\hline 12. & Do you find it difficult to do sums in your head without using your fingers or paper? & & \\
\hline 13. & When using the telephone, do you tend to get numbers mixed up when you dial? & & \\
\hline 14. & Do you find it difficult to say the months of the year forwards in a fluent manner? & & \\
\hline 15. & Do you find it difficult to say the months of the year backwards? & & \\
\hline 16. & Do you mix up dates and times and miss appointments? & & \\
\hline 17. & When writing cheques do you frequently find yourself making mistakes? & & \\
\hline 18. & Do you find forms difficult and confusing? & & \\
\hline 19. & Do you mix up bus numbers like 95 and $59 ?$ & & \\
\hline 20. & Did you find it hard to learn your multiplication tables at school? & & \\
\hline
\end{tabular}

Table 1: The Adult Dyslexia Checklist (Vinegrad, 1994) 


\begin{tabular}{|c|c|c|c|c|c|c|c|}
\hline & \multicolumn{7}{|c|}{$p$-value } \\
\hline & $\begin{array}{l}\text { Dyslexia } \\
\text { Score }\end{array}$ & Surface & Vision & $\begin{array}{c}\text { Dyslexia } \\
\text { Score x } \\
\text { Surface }\end{array}$ & $\begin{array}{l}\text { Surface } \mathrm{x} \\
\text { Vision }\end{array}$ & $\begin{array}{c}\text { Dyslexia } \\
\text { Score x } \\
\text { Vision }\end{array}$ & $\begin{array}{c}\text { Surface } \mathrm{x} \\
\text { Vision x } \\
\text { Dyslexia } \\
\text { Score }\end{array}$ \\
\hline Anterior-Posterior & $\begin{array}{l}<0.001 \\
{[4.2]}\end{array}$ & $\begin{array}{l}<0.001 \\
{[417.1]}\end{array}$ & $\begin{array}{l}<0.001 \\
{[203.6]}\end{array}$ & NS [1.2] & $\begin{array}{l}<0.001 \\
{[22.0]}\end{array}$ & NS [1.0] & NS [0.8] \\
\hline Lateral & $\begin{array}{c}<0.001 \\
{[8.3]}\end{array}$ & $\begin{array}{l}<0.001 \\
{[952.3]}\end{array}$ & $\begin{array}{l}<0.001 \\
{[100.8]}\end{array}$ & NS [1.4] & $\begin{array}{l}<0.001 \\
{[35.0]}\end{array}$ & NS [0.8] & NS [0.6] \\
\hline
\end{tabular}

Table 2: Statistical evaluation of the torque variance values using the GLM univariate ANOVA method showing the effect of dyslexia score, surface, vision and their interactions. The notation " $<0.001$ " means that the $p$-value is smaller than 0.001 , and "NS" signifies no significant difference. F-values are presented within the squared parentheses. 


\section{Figure legends}

Figure 1: The significant correlations between dyslexia scores and torque variance $\left[(\mathrm{Nm} /(\mathrm{kg} \cdot \mathrm{m}))^{2}\right]$ for $(\mathrm{A})$ the anteroposterior direction on foam with eyes closed $(\mathrm{A})$ and in the lateral direction on a foam surface with eyes closed (B) and eyes open (C). 95\% Confidence Interval of mean shown with the line of best fit.

Figure 2: Anteroposterior (A) and lateral (B) torque variance for the non-dyslexic and dyslexic group with eyes open and closed on the foam surface and on the firm surfaces. Error bars show the Standard Error of the Mean (SEM). * denotes $p<0.05$. 

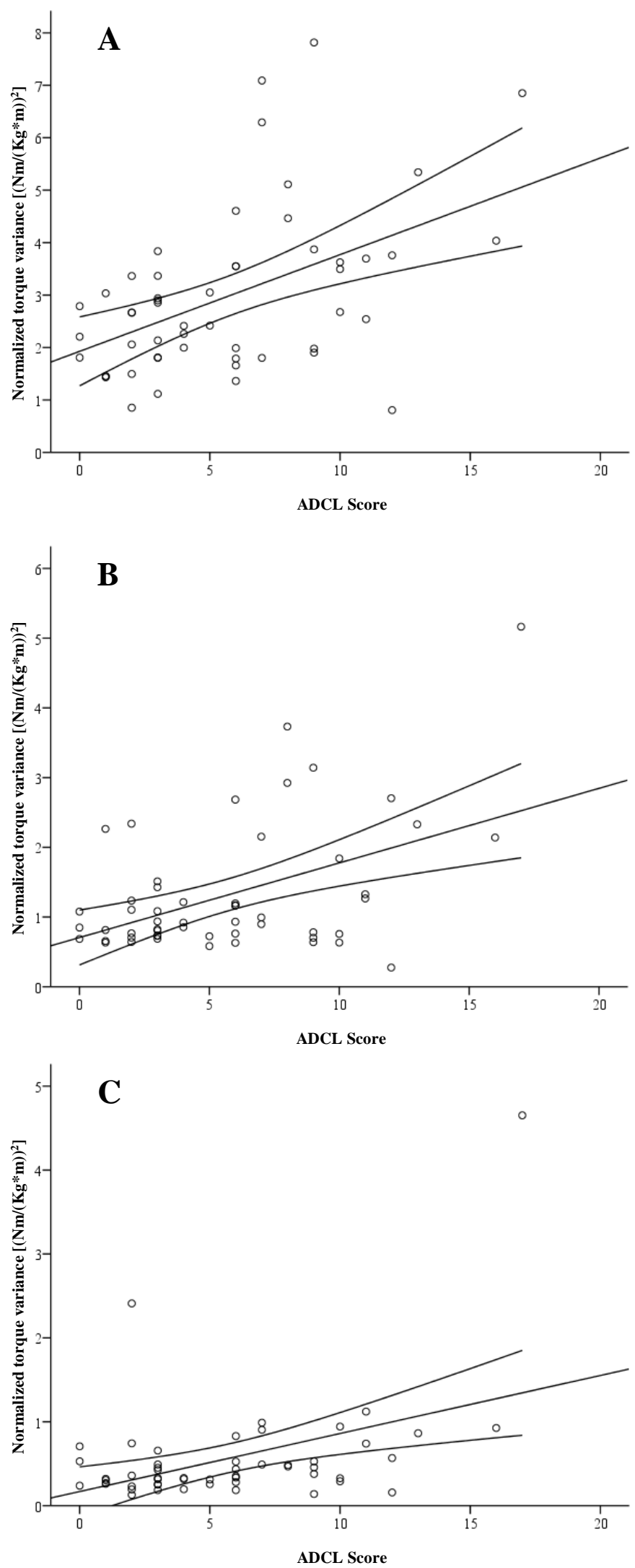

Figure 1 

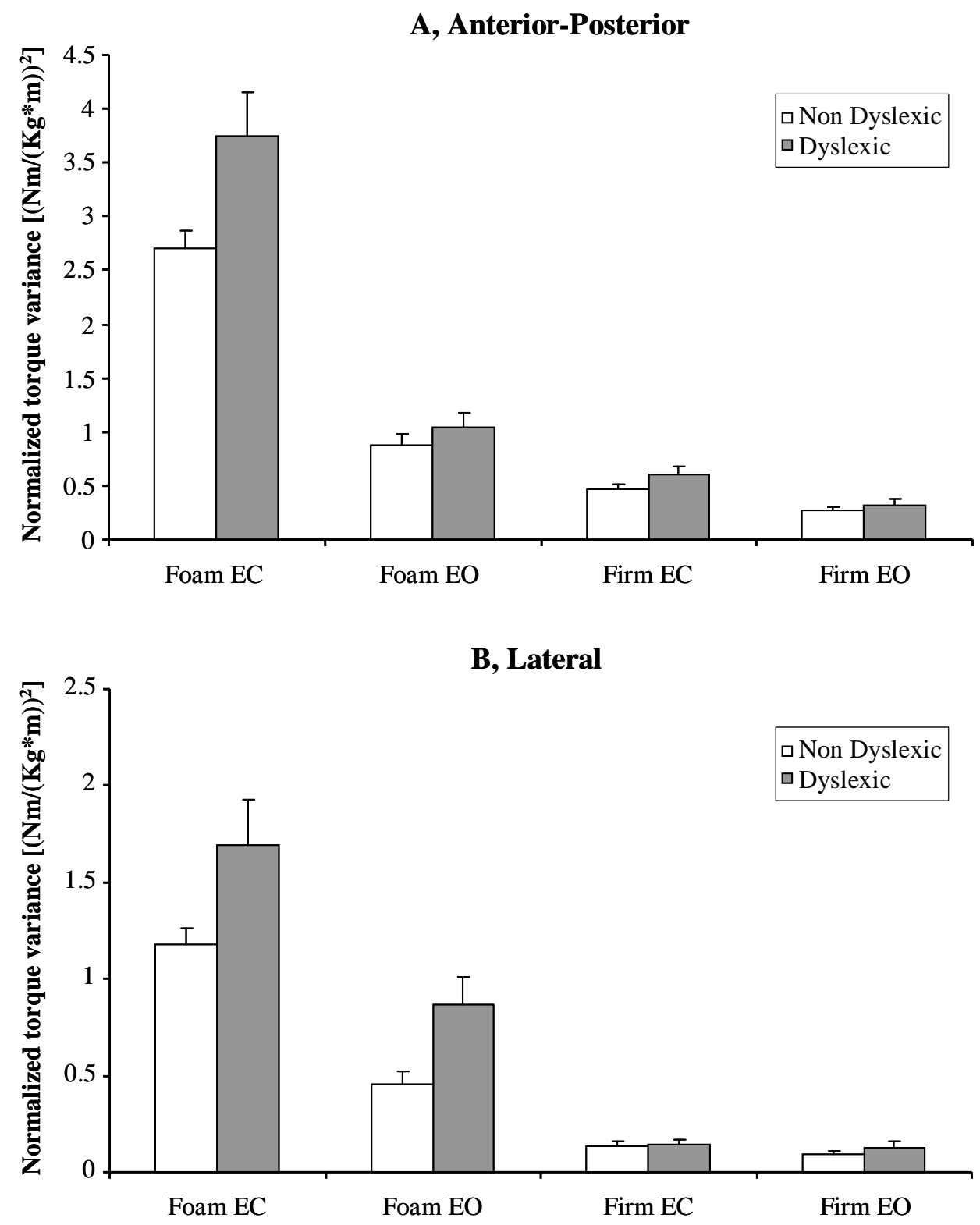

Figure 2 